\title{
ANÁLISE DA CONSTITUCIONALIDADE DO REQUISITO BAIXA RENDA NA CONCESSÃO DE BENEFÍCIO DE AUXÍLIO-RECLUSÃO
}

\section{ANALYSIS OF THE CONSTITUTIONALITY OF THE LOW INCOME REQUIREMENT IN GRANTING THE BENEFIT OF CONFINEMENT-ASSISTANCE}

\author{
Luiz Rodrigues Araújo Filho ${ }^{1}$ \\ Glauciene da Mota Barros Caetano ${ }^{2}$
}

\section{RESUMO}

Esta produção apresenta uma análise da constitucionalidade do requisito baixa renda na concessão do benefício de auxílio-reclusão. Para tal realiza um levantamento histórico das políticas públicas do Estado, e ainda o papel da igreja ao longo da história no assistencialismo. Este trabalho apresenta os requisitos para a concessão do auxílio-reclusão, discute as atuais regras que garantem esse direito aos beneficiários, com destaque especial para a Constituição Federal, que tem a previsão desse benefício, e a Lei no 8.213/1991, que o regulamenta. Nesse viés deixa-se demonstrado a jusfundamentalidade do benefício auxílio-reclusão, a partir do estudo da Teoria do Mínimo Existencial e do Risco Social, que são base para concessão do benefício em comento, faz-se aqui uma discussão do benefício frente à Dignidade da Pessoa Humana, princípio fundamental do Estado Brasileiro. Trata também, das alterações na concessão do auxílio-reclusão trazidas pela Emenda Constitucional no 20 de 1998. Por fim, conclui-se que a referida Emenda é inconstitucional, pois leva em consideração, no momento da concessão do benefício de auxílio-reclusão, a renda do segurado preso, e não a do beneficiário.

Palavras-Chave: Auxílio-Reclusão; Baixa Renda; Constitucionalidade; Contribuinte; Emenda Constitucional no 20/1998.

\footnotetext{
${ }^{1}$ Mestre em Direito Tributário Contemporâneo pela Universidade Católica de Brasília, Doutorando em Ciências Jurídicas e Sociais pela UMSA, Auditor Fiscal da Receita Estadual do Tocantins. Professor de Direito Tributário da Faculdade Católica do Tocantins.

${ }^{2}$ Bacharelanda em Direito pela Faculdade Católica do Tocantins. Professora da Educação Básica da Rede Estadual de Ensino do Estado do Tocantins. E-mail: glaucienedamota@bol.com.br
} 


\begin{abstract}
This production presents an analysis of the constitutionality of the low income requirement in granting the benefit confinement-assistance. For this realization a historical survey of public policies of the State, and still the role of the church throughout history without assistance. This paper presents the requirements for the granting of confinement-assistance, discusses the current rules that guarantee this right to beneficiaries, with special emphasis on the Federal Constitution, which provides for this benefit, and Law No. 8.213 / 1991, which regulates it. This bias demonstrates the jusfundamentality of the confinement-assistance benefit, based on the study of the Theory of Existential Minimum and Social Risk, which are the basis for granting the benefit in question, here is a discussion of the benefit against the Dignity of the Human Person, the fundamental principle of the Brazilian State. It also deals with the changes in the granting of confinement-assistance brought by Constitutional Amendment No. 20 of 1998. Finally, it is concluded that this Amendment is unconstitutional, since it takes into account the income of the insured inmate, and not that of the beneficiary, at the time of granting the confinementassistance.
\end{abstract}

Keywords: Confinement-Assistance; Low Income; Constitutionality; Taxpayer; Constitutional Amendment no. 20/1998.

\title{
1. CONTEXTO HISTÓRICO
}

Estado, ao longo dos anos, tem se mostrado preocupado com as políticas públicas e sociais de assistencialismo, tendo em vista seu papel de garantidor dos direitos fundamentais do indivíduo.

Para Niluk (2014, online) gerir os direitos fundamentais dos cidadãos passou a ser preocupação do governo. Em 1883, na Alemanha por meio da iniciativa do "Chanceler de Ferro" Otto Von Bismarck, foi estatuído o primeiro sistema de seguridade social devido à necessidade de progresso industrial e ideias socialistas.

Em 1891, a Igreja também se manifestou através da Encíclica Papal Rerum Novarum $^{3}$, de Leão XVIII, sugerindo um sistema de pecúlio com vistas a compensar o

\footnotetext{
${ }^{3}$ De acordo com Bortoli e Pereira (2014, Online) em 1891, o Papa Leão XIII publicou a Encíclica Rerum Novarum, documento que teve uma forte ingerência nas relações sociais laborais de vários países, visto que sem abandonar os dogmas e os princípios da igreja, destacou-se a premente necessidade de buscar meios alternativos para conseguir uma convivência entre o capital e o trabalho. A Encíclica em comento será mais discutida na próxima seção. BORTOLI, Nádia Carrer de Ruman de; PEREIRA, Wander. Uma análise da Rerum Novarum e suas influências no Direito do Trabalho. Jus: Online, 2014. Disponível em: < https://jus.com.br/artigos/29884/uma-analise-da-rerum-novarum-e-suas-influencias-no-direito-dotrabalho>. Acesso em: 26 out. 2017.
} 
trabalhador, que através de suas economias terem suas reservas em caso de necessidade (NILUK, 2014, Online).

De acordo com Paiva (2014, p. 121) em 1960 a política de auxílio do indivíduo privado de sua liberdade em razão de crime por ele praticado, foi estatuída no Brasil, por meio da Lei n 3.807/1960, denominada "Lei Orgânica da Previdência Social". Essa lei tinha o objetivo de garantir subsistência aos dependentes do segurado, que teve ceifada sua liberdade, e encontravam-se cumprindo penas em regime aberto, semiaberto ou fechado.

Segundo Dantas e Rodrigues (2009, apud PAIVA, 2014, p.121) "o auxílioreclusão é o único benefício, nesses moldes, conhecido no mundo".

Com o advento da Lei de Execução Penal em 1984 (LEI № 7.210/1984) vários direitos dos presos tiveram salvaguarda legal, como por exemplo, à integração social, a garantia à alimentação, ao trabalho, à saúde, à assistência e também à previdência social.

Com a promulgação da Constituição da República Federativa do Brasil de 1988 CRFB/1988 o benefício previdenciário de auxílio-reclusão passou a possuir status de norma constitucional, sofrendo algumas modificações com a Emenda Constitucional no 20 de 1998, que alterou o art. 201, inciso IV, ipsis litteris:

Art. 201. A previdência social será organizada sob a forma de regime geral, de caráter contributivo e de filiação obrigatória, observados critérios que preservem o equilíbrio financeiro e atuarial, e atenderá, nos termos da lei, a:

[...]

IV - salário-família e auxílio-reclusão para os dependentes dos segurados de baixa renda;

A referida Emenda Constitucional configurou novas regras para concessão do benefício, estabelecendo que apenas aqueles que se encontrem na condição de segurado, e que se enquadrem como baixa renda, fossem contemplados, sendo o recurso destinado apenas às pessoas presas consideradas extremamente pobres. 
Entretanto, observa-se que a Emenda não definiu parâmetros para a categoria baixa renda, definindo apenas o teto para ter acesso ao benefício, que é atualizado anualmente pelos mesmos índices de reajustes dos benefícios da previdência social por meio de portarias interministeriais do Ministério da Previdência Social.

Como o requisito da baixa renda restringiu o direito de recebimento do benefício pelos que contribuem acima do teto fixado pelo Regime Geral de Previdência Social RGPS, várias ações judiciais foram interpostas, arguindo que não ficou expressamente estabelecido, se a baixa renda tem referência o segurado ou seus dependentes.

O entendimento do Ministro Cezar Peluso no julgamento do Recurso Especial no 587.365/SC foi que o benefício de auxílio-reclusão se destina à sobrevivência dos dependentes e, por isso, o que deve ser verificado para a concessão é a renda familiar. "Se o segurado tiver baixa renda, mas seus dependentes não necessitem de auxílio nenhum, o benefício perde a razão de ser".

Todavia, o entendimento majoritário doutrinário e jurisprudencial têm se firmado no sentido de que a definição de renda, para fins de concessão do benefício de auxílioreclusão que deve ser considerada no ato da concessão do benefício é a da pessoa segurada e não a dos dependentes (RAUPP, 2009, p.67).

Para melhor compreensão do funcionamento desse benefício, é necessário fazer uma análise acerca de sua caracterização, importância, limitação e fundamentação. Isso será feito nas próximas seções.

\subsection{A ENCÍCLICA PAPAL RERUM NOVARUM}

Na Carta Encíclica Papal Rerum Novarum (das coisas novas) Papa Leão XIII tutela os direitos fundamentais do trabalhador: salário justo, carga de trabalho das mulheres e crianças compatíveis com suas capacidades, repouso dominical e a limitação das horas de trabalho.

Além de apresentar questões sobre a revolução industrial e as sociedades 
democráticas no final do século XIX, a encíclica também discutiu as relações entre o governo, o trabalho e a Igreja. E sobre alguns princípios inerentes à justiça, e a intervenção do Estado na economia em defesa dos menos favorecidos.

A igreja se manifesta, à luz do evangelho, dos ensinamentos cristãos e do documento Rerum Novarum, a fim de apresentar soluções para os problemas sociais vividos pela humanidade, pois a competência da Igreja em anunciar os princípios morais, ainda que referente à ordem social, e pronunciar-se a respeito de qualquer questão humana, enquanto o exigirem os direitos fundamentais da pessoa humana ou a salvação das almas. (PONTIFÍCIO CONSELHO, 2004).

Pela relevância pública do tema, após cem anos de publicação da primeira encíclica social da Igreja, em 1991, assinada pelo Papa Leão XIII, o S. Padre Papa João Paulo II se manifestou em favor da Rerum Novarum, pois o documento despertou os católicos e o mundo para a procura de mais justiça e fraternidade. A encíclica abriu o caminho aos sucessivos pronunciamentos da Igreja sobre a questão social (A ENCÍCLICA RERUM NOVARUM, 1991, online).

Tal documento foi tido como revolucionário na sua época e teve adesão de autoridades eclesiais do mundo inteiro, com o objetivo de defender os interesses dos operários, rechaçando o capitalismo liberal e reforçando o dever do estado de manutenção da previdência social.

[...] a autoridade pública deve também tomar as medidas necessárias para salvaguardar os interesses da classe operária. Se ela faltar a isto, violará a estrita justiça, que quer que a cada um seja dado o que the é devid ( $A$ ENCÍCLICA RERUM NOVARUM, 1991, online).

$\mathrm{Na}$ linha central da encíclica, constam obrigações como a necessidade de se pagar salário justo ao trabalhador, bem como vislumbra a economia como conciliação das classes. Salário justo é entendido pelo Pontífice como aquele que garante ao operário condições de vida digna, adequada condição de subsistência familiar: 
O operário que perceber um salário suficiente para ocorrer com desafogo às suas necessidades e às da sua família, se for prudente, seguirá o conselho que parece dar-lhe a própria natureza. (CARTA ENCÍCLICA RERUM NOVARUM, 1891, Online, № 28).

Neste sentido, observa-se que a preocupações por parte da igreja em prover subsistência para as famílias remota de longa data, e que embora as circunstâncias se atualizem, continua patente a ideia que tendo os operários cumprido suas obrigações trabalhistas cabe ao Estado devolver por meio de benefícios seus recolhimentos para atender suas necessidades.

Feito esse breve histórico, na seção seguinte, esta produção detalhará os requisitos bem como os fundamentos jurídicos do benefício de auxílio-reclusão, que, como já visto acima, tem base histórica tanto na igreja quanto no próprio Estado.

\section{REQUISITOS PARA CONCESSÃO DO BENEFÍCIO DE AUXÍLIO-RECLUSÃO}

Com vistas a garantir a subsistência familiar, o auxílio-reclusão é devido ao dependente do segurado detento ou recluso, que teve sua liberdade mitigada em razão de ato delituoso que tenha cometido, e que o último salário de contribuição seja igual ou inferior a $\mathrm{R} \$ 1.292,43$ (um mil, duzentos e noventa e dois reais e quarenta e três centavos) $)^{4}$.

De acordo com Tavares (2014, p. 209) não terá direito ao auxílio-reclusão os dependentes daqueles que ainda que presos receber remuneração da empresa ou estiver em gozo de auxílio doença ou aposentadoria.

Além da Previsão Constitucional, o auxílio-reclusão possui também disposição expressa no art. 80 da Lei no 8.213/1991, in verbis:

\footnotetext{
${ }^{4}$ De acordo com a Portaria MF no 8 de 13 de janeiro de 2017. Disponível em: < http://www.previdencia.gov.br/servicos-ao-cidadao/todos-os-servicos/auxilio-reclusao >. Acesso em: 10 maio 2017.
} 
Art. 80 - O auxílio-reclusão será devido, nas mesmas condições da pensão por morte, aos dependentes do segurado recolhido à prisão, que não receber remuneração da empresa nem estiver em gozo de auxílio-doença, de aposentadoria ou de abono de permanência em serviço.

Parágrafo único. O requerimento do auxílio-reclusão deverá ser instruído com certidão do efetivo recolhimento à prisão, sendo obrigatória, para a manutenção do benefício, a apresentação de declaração de permanência na condição de presidiário.

Para Eduardo (2013, p. 457), o pressuposto para a concessão do benefício são os fatos geradores recolhimento do segurado à prisão e baixa renda.

$\mathrm{Da}$ leitura do texto legal se conclui que o benefício será destinado aos dependentes do segurado preso que devem apresentar à Previdência Social, atestados ou certidões emitidas por autoridade competente que comprovem a continuidade da prisão.

Essa exigência faz-se necessária, para que alimentando os dados cadastrais do benefício social, ocorra a verificação de vínculos trabalhistas, e evite fraudes, uma vez que o cumprimento da pena pode não impedir que o segurado exerça trabalho remunerado, desta forma injustificando o recebimento desse.

Essa apresentação de certidão é realizada, para caso seja posto em liberdade condicional, fuja da prisão ou passe a cumprir pena em regime aberto, o benefício seja encerrado. E com a morte do segurado o beneficio é convertido em pensão nos termos do art. 15, inciso IV, da Lei no 8.213/1991.

A duração do benefício em relação ao conjugue/companheiro pode variar de acordo com a idade desse, e com o tempo de contribuição do segurado à previdência.

Quando ocorre até 18 meses de contribuição, o benefício tem duração de quatro meses, caso ultrapasse esse tempo o auxílio se estende de acordo com a idade do dependente na data da prisão do contribuinte (LEI № 8.213/1991).

Essa duração é também modificada com a adesão de um novo estado civil do recluso nos últimos dois anos. Já em referência aos descendentes, o benefício é devido até os 21 anos de idade ou vitalício em caso de invalidez.

A cota do auxílio-reclusão deve ser dividida igualmente entre os dependentes, 
porém, quando atingem maioridade, é redistribuída aos demais.

De acordo com Tavares (2014, p. 209-210) o auxílio-reclusão é incompatível com a prisão processual civil, e o valor do benefício corresponde à integralidade do salário de benefício.

\subsection{A JUSFUNDAMENTALIDADE DO BENEFÍCIO AUXÍLIO-RECLUSÃO}

O fundamento deste benefício, segundo Paula (2016, p. 237) está em amparar a família do segurado que devido recolhimento à prisão deixou de trabalhar e prover a subsistência de sua família. É o efetivo atendimento das necessidades básicas e essenciais dos seus dependentes, evitando muitas vezes o risco social por conta da perda da renda.

E como o sistema penitenciário do Brasil não oferece mecanismos de ressocialização, o meio de coerção é parcialmente eficaz, pois tem trazido doenças físicas e mentais, de forma que após o cárcere o preso traz maiores problemas para a sociedade.

De acordo com o preâmbulo da Constituição da Organização Mundial da Saúde - OMS, de 1946 o conceito de saúde não se limita à ausência de doenças, mas é a saúde:

um estado de completo bem-estar físico, mental e social, e não consiste apenas na ausência de doença ou de enfermidade.

Gozar do melhor estado de saúde que é possível atingir constitui um dos direitos fundamentais de todo o ser humano, sem distinção de raça, de religião, de credo político, de condição econômica ou social.

É evidente que se sua condição econômica for comprometida poderão desencadear outros problemas, daí a necessidade de intervenção do Estado em prover o equilíbrio financeiro e social para que não fiquem desamparados seus dependentes até que ele reestabeleça a condição de prover novamente suas subsistências.

A segurança social é uma prestação fundamental estatuída internacionalmente 
em 1948 com a Declaração Universal dos Direitos Humanos - DUDH ${ }^{5}$ que apresenta um rol de prestações fundamentais ao individuo, elencadas e discutidas a seguir:

Art. XXIII, 3. Todo ser humano que trabalha tem direito a uma remuneração justa e satisfatória, que lhe assegure, assim como à sua família, uma existência compatível com a dignidade humana e a que se acrescentará se necessário, outros meios de proteção social.

Art. XXV, 1. Todo ser humano tem direito a um padrão de vida capaz de assegurar-lhe, e a sua família, saúde e bem-estar, inclusive alimentação, vestuário, habitação, cuidados médicos e os serviços sociais indispensáveis, e direito à segurança em caso de desemprego, doença, invalidez, viuvez, velhice ou outros casos de perda dos meios de subsistência em circunstâncias fora de seu controle.

Ainda que o contribuinte usufrua indiretamente o benefício por meio de seus dependentes, isso o deixa em uma situação mais confortável, pois o auxílio representa uma contraprestação àquele que se encontra incapaz de prover sustento à sua família, devido ter cumprido regularmente sua responsabilidade fiscal junto à previdência social.

Chies e Passos ${ }^{6}$, em pesquisa realizada em 2012, concluíram que a tendência de ser o auxílio-reclusão alvo de tantas críticas é resultado de um populismo punitivo construído socialmente e sustentado pelas principais instituições sociais, aliado à falta de informação das pessoas quanto aos pormenores do benefício.

As sanções aplicadas ao preso não podem ser estendidas aos seus dependentes, pois além de não terem cometido os crimes, não são culpados pelo baixo nível de informação da maioria da população em relação a este benefício e nem da imposição estatal sobre eles.

O princípio da personalidade da pena, previsto no art. 5ำ XVL, da CRFB de 1988 e no Item 3 do Art. 5ำ da Convenção Interamericana de Direitos Humanos - $\mathrm{CIDH}$, diz que somente o condenado deve ser responsabilizado pelo crime e obrigado a cumprir pena por isso, resguardando a integridade dos seus familiares.

5 Disponível em: <http://www.onu.org.br/img/2014/09/DUDH>. Acesso em: 14 mar. 2017.

6 CHIES, L. A. B.; PASSOS, R. A. Auxílio-reclusão: a bizarra transmutação de um direito social e sua colonização perversa por um populismo punitivo, 2012, p. 285. 
Mas essa proteção aos dependentes fica desassistida por conta do risco social que representam, tendo em vista que com o segurado preso ocorre a perda do suporte financeiro, cabendo ao Estado a continuidade de sua manutenção.

\subsection{TEORIA DO MÍNIMO EXISTENCIAL E DO RISCO SOCIAL}

A seguridade social objetiva a proteção social, com vistas a garantir os direitos mínimos sociais para que todos sobrevivam com dignidade.

Nesse contexto, Canotilho (2010, p. 18), diz que tal princípio fundamenta o Estado Social e significa justamente uma postulação de garantia e do reconhecimento de direitos sociais, tendo por definição:

[...] uma autorização constitucional no sentido de o legislador democrático e os outros órgãos encarregados da concretização político-constitucional adotarem as medidas necessárias para a evolução da ordem constitucional sob a óptica de uma justiça constitucional nas vestes de uma justiça social.

É tão importante que é consagrado pela Doutrina como sendo o núcleo do Princípio da Dignidade da Pessoa Humana, previsto no artigo 1ㅜ, III da CRFB.

A garantia do mínimo existencial refere-se a um mínimo de condições oferecidas pelo Estado a que todo indivíduo tem direito, a fim de promover qualidade de vida e desenvolvimento humano. Para Torres (2009, p. 20) "deve ser mensurada pela garantia dos mínimos sociais e das prestações positivas de justiça distributiva ligada à educação, saúde, moradia e demais direitos sociais".

Dessa forma, o contribuinte deve ter o retorno de todo o período em que contribuiu para manutenção do sistema, pois além da situação de vulnerabilidade em que se encontram - o cárcere, são estereotipados pela sociedade que não consideram possível a reinserção e reintegração social do preso. 


\section{ANALISE DA ALTERAÇÃO CONSTITUCIONAL DA EMENDA № 20/1998}

A Emenda Constitucional ํㅜ 20/98 consubstanciou novas regras de concessão do benefício auxílio-reclusão, enquadrando apenas os dependentes dos segurados de baixa renda, conforme estabelecido nas leis a seguir:

Art. 201. A previdência social será organizada sob a forma de regime geral, de caráter contributivo e de filiação obrigatória, observados critérios que preservem o equilíbrio financeiro e atuarial, e atenderá, nos termos da lei, a: Redação dada pela Emenda Constitucional no 20, de 1998).

IV - salário família e auxílio-reclusão para os dependentes dos segurados de baixa renda;

Já que o Regime Geral de Previdência Social - RGPS nos planos de previdência social, mediante contribuição deverão atender essa demanda, torna-se fundamental analisar como parte dos contribuintes fica desassistida dessa política, é o caso do contribuinte de renda superior à estabelecida pelo Regime.

De acordo com Ibrahim (2014, p. 686) A limitação deste benefício aos dependentes do segurado de baixa renda à percepção desta prestação, trazida pela emenda em epígrafe, foi de extrema infelicidade, pois excluiu da proteção diversos dependentes, cujos segurados estão fora do limite de baixa renda. Tais dependentes poderão enfrentar situação difícil, com a perda da remuneração do segurado.

Para Ibrahim (2014, p. 686), essa alteração é inconstitucional, haja vista gerar uma diferenciação desprovida de qualquer razoabilidade, pois o segurado, mesmo com remuneração vultuosa, poderá deixar a família em situação de necessidade mais gravosa do que outra família, mais humilde, mas que tenha outras fontes de renda. Para piorar, a inércia legislativa em disciplinar conceito derradeiro de baixa renda provoca, como se percebe com facilidade, discrepância ainda maior, possibilitando que dependentes percam o benefício por centavos ou mesmo pelo fato do segurado ter sido preso no mês de férias, no qual recebe, além do salário, mais $1 / 3$ do adicional constitucional o que não raramente produz resultado maior do limite vigente. 
Tendo em vista que o dependente desse contribuinte necessita de manutenção da vida, saúde e bem estar, e que embora não esteja dentro dos padrões de baixa renda carece de suprimento de suas necessidades, isso se faz objeto de estudo no presente trabalho.

Contudo, relevante é analisar que a Emenda deixou descoberta uma grande parcela da população contribuinte, pois reflete diretamente em seus direitos previdenciários, civis e naturais.

Essa restrição expressa a redução de direitos dos contribuintes com renda superior à estabelecida, representa a perda do retorno do seguro em sua integralidade.

\subsection{DA INCONSTITUCIONALIDADE DO REQUISITO BAIXA RENDA}

Para Raupp (2009, p. 68), a proteção social dirigida aos dependentes de segurado recolhido à prisão é direito fundamental previsto na Constituição, a ser amparado pelo sistema previdenciário.

Contudo, percebe-se a inconstitucionalidade da Emenda ํo 20, que exclui os dependentes do segurado cuja renda ultrapasse determinado valor, dessa proteção social.

E que independente da renda que o Segurado detenha, a condição de contribuinte e recluso é a mesma, sendo ele carente ou abastado, seus dependentes necessitam também de manutenção.

Daí a necessidade da ampliação da norma, pois não é igualitário deixar desamparados os dependentes de segurado impedido de trabalhar só porque auferiu renda superior ao limite legal.

Em contraposição à pensão por morte essa assistência seria devida, pois diz respeito à substituição da renda do segurado ausente, já que para este é assistido independente renda auferida.

Caso o pagamento de pensão por morte aos dependentes do segurado fosse 
apenas para os dependentes baixa renda as famílias detentoras de melhor nível econômico não seriam também contempladas.

Neste contexto, o desamparo será o mesmo caso os dependentes não aufiram renda própria, além de que possuir renda superior a estabelecida pela previdência social não significa que seus dependentes tenham garantida a sua subsistência.

O objetivo da seguridade social de universalidade da cobertura e do atendimento foi suprimido, (art. 194, parágrafo único, I, da Constituição da República), pois excluiu da proteção social parte dos que dela necessitam.

A questão em epígrafe encontra-se sob análise do Supremo Tribunal Federal, sendo reconhecida como matéria de repercussão geral, objeto da Súmula no 5 :

(RE 587.365-SC, Relator Min. Ricardo Lewandowski). Ementa: CONSTITUCIONAL E PREVIDENCIÁRIO. BENEFÍCIOS. AUXÍLIORECLUSÃO. RENDA A SER CONSIDERADA. SEGURADO PRESO. ALEGAÇÃO DE AUSÊNCIA DE PREQUESTIONAMENTO. INVIABILIDADE. ALEGAÇÃO DE INEXISTÊNCIA DE PRELIMINAR DE REPERCUSSÃO GERAL. IMPROCEDÊNCIA. INTIMAÇÃO DO ACÓRDÃO RECORRIDO ANTERIOR A 03/05/2007. 1. O Supremo Tribunal Federal, no julgamento do RE 387.265/SC, sob o regime da repercussão geral, consolidou entendimento no sentido de que a renda a ser considerada para a concessão do auxílio-reclusão é a do segurado de baixa renda, e não a dos seus dependentes. 2. Agravo regimental a que se nega provimento.

Embora haja esse entendimento, é importante observar que a renda do dependente é que deveria ser considerada, tendo em vista que o benefício é destinado eles, que muitas vezes se encontram em situação de vulnerabilidade sem o mantenedor, acarretando assim uma injustiça material.

\subsection{VIOLAÇÃO AO PRINCÍPIO DA ISONOMIA}

O princípio da isonomia arbitra sobre a maneira igualitária, na qual, todos devem ser tratados como iguais perante a lei. E que na aplicação da lei em epígrafe, notamos que este fundamento foi ferido, pois se a previsão é de tratamento igualitário a todos, conforme determina 0 art. $5^{\circ}$ da Carta Magna, neste contexto há ocorrência de 
favorecimento de apenas uma classe, que é a que se enquadra dentro do critério para recebimento do benefício, ficando desassistida a classe contribuinte acima do teto estabelecido.

Os direitos e garantias individuais, considerados cláusulas pétreas não podem ser abolidos da Constituição, assim também o princípio da isonomia que tem finalidade de reduzir as desigualdades sociais ser eficaz, pois a pena não pode passar da pessoa do condenado, e quem sustenta sua família não é o Estado e sim o recluso que embora esteja impossibilitado de exercer suas atividades laborais, teve a responsabilidade de cumprir com suas obrigações fiscais.

\section{CONSIDERAÇÕES FINAIS}

É sabido que a família do encarcerado sofre consequências prejudiciais ao relacionamento social, e que esses perdem oportunidades por possuir sobre a guarda estatal um ente aprisionado, que muitas vezes é o único provedor da subsistência familiar.

Ademais, grande parte das famílias afetadas desconhecerem esse benefício poucos são os contemplados, pois o assistencialismo é limitado à classe contribuinte de um teto incomum a grande parte da população brasileira.

Mesmo tendo aumentado o número de beneficiários, nota-se também que embora uma parte da sociedade tenha sido contemplada muitos são os excluídos, pois o sistema é restrito apenas à classe contribuinte do teto apresentado como máximo.

Importante salientar que se ocorre a contribuição mesmo que a participação do repasse para segurança seja ínfimo em relação a outros no orçamento da previdência vale ressaltar que não permitir acesso a ele é invalidar os fundamentos estabelecidos da Constituição da República Federativa do Brasil.

Por outro lado as políticas públicas de ressocialização do preso surtirão efeito progressivo em resposta à sociedade, pois se a família dispuser de condições mínimas 
de vida digna estará preparada para recepcioná-lo quando este estiver em liberdade.

\section{REFERÊNCIAS}

A ENCÍCLICA Rerum Novarum. Revista Per (6261). In: de L'OSSERVATORE ROMANO, ed. francesa, 05/03/91, p.2. Disponível em: < http://www.pr.gonet.biz/kb_read.php?num=245 >. Acesso: 28 out. 2017.

BRASIL. Constituição (1988). Constituição da República Federativa do Brasil: promulgada em 5 de outubro de 1988. Brasília, DF; 1988. Disponível em:< http://www.planalto.gov.br/ccivil_03/constituicao/ConstituicaoCompilado.htm>. Acesso em: 08 abr. 2017.

. Lei n. 8.213, de 24 de julho de 1991. Dispõe sobre os Planos de Benefícios da Previdência Social e dá outras providências. Brasília, DF; 1991. Disponível em: < http://www.planalto.gov.br/ccivil_03/leis/L8213cons.htm>. Acesso em: 20 abr. 2017.

CANOTILHO, J J.G. O Direito Constitucional como ciência de direção - 0 núcleo essencial de prestações sociais ou a localização incerta da socialidade (contributo para a reabilitação da força normativa da Constituição Social), 2010. P 18.

CARTA ENCÍCLICA RERUM NOVARUM. Libreria Editrice Vaticana: 1891. Disponível em:<http://w2.vatican.va/content/leo-

xiii/pt/encyclicals/documents/hf_lxiii_enc_15051891_rerum-novarum.html>. Acesso em: 28 out. 2017.

CHIES, L. A. B.; PASSOS, R. A. Auxílio-reclusão: a bizarra transmutação de um direito social e sua colonização perversa por um populismo punitivo. Textos \& Contextos, Porto Alegre, v. 11, n. 2, p. 273-291, ago./dez. 2012.

Constituição da OMS (preâmbulo). Disponível em:< http://www.direitoshumanos.usp.br/index.php/OMS>. Acesso em 08 abr. 2017.

DANTAS, E. de A.; RODRIGUES, E. B. de O. Auxílio-reclusão: uma abordagem conceitual. Informe de Previdência Social, v. 21, n. 6, p. 1-13, jun. 2009.

MARTINEZ, Wladimir Novaes. Curso de direito previdenciário, tomo II: previdência social. 2. Ed. São Paulo, LTr, 2003. 
MORAES, Alexandre de. Direito constitucional. 11. Ed. São Paulo: Atlas, 2002.

NILUK, Carla. Breve histórico da seguridade e previdência social. JusBrasil. 2014. Disponível em: <https://carlaniluk.jusbrasil.com.br/artigos/171088435/breve-historico-daseguridade-e-previdencia-social>. Acesso em: 28 out. 2017.

PAIVA, Juliana Medeiros. Auxílio-Reclusão: um direito restrito. R. Katál., v. 17, n. 1, p. 120-129. Florianópolis: 2014. Disponível em:

<http://www.scielo.br/pdf/rk/v17n1/a13v17n1. pdf>. Acesso em: 10 maio 2017.

PAULA, Raquel Tavares. O direito fundamental social à prestação previdenciária: a importância do auxílio-reclusão à luz do princípio da vedação ao retrocesso social. Revista da Defensoria Pública da União/ Defensoria Pública da União. - N. 9 (jan./dez.2016). Brasília: DPU, 2016. v.; 28,cm.

PONTIFÍCIO CONSELHO. Compêndio da Doutrina Social da Igreja. Vaticano, 2004. Disponível: < http://www.vatican.va/roman_curia/pontifical_councils/justpeace/documents/rc _pc_justpeace_doc_20060526_compendio-dott-soc_po.html>. Acesso em: 28 out. 2017.

RAUPP, D. Auxílio-reclusão: inconstitucionalidade do requisito baixa renda. Revista CEJ, ano XIII, n. 46, p. 62-70, jul./set. 2009.

Revista Brasileira de Direito Previdenciário. v.1 (fev./mar. 2011) - Porto Alegre: Magister, 2011 - Bimestral, v.15 (jun./jul.2013).

TAVARES, Leonardo Marcelo. Direito previdenciário: regime geral de previdência social e regras constitucionais dos regimes próprios de previdência social. 15. Ed. rev. atual. Niterói: Impetus, 2014.

TORRES, R. L. O Direito ao Mínimo Existencial. 2009. p. 20. 